\title{
Molybdenum Phosphide Flakes Catalyze Hydrogen Generation in Acidic and Basic Solutions
}

\author{
Zhongzhong Chen, Cuncai Lv, Zhibo Chen, Lihuang Jin, Jie Wang, Zhipeng Huang* \\ China-Australia Joint Research Center for Functional Molecular Materials, Scientific Research Academy, Jiangsu \\ University, Jiangsu, China \\ Email: ${ }^{*}$ zphuang@ujs.edu.cn
}

Received 27 September 2014; revised 12 November 2014; accepted 29 November 2014

Copyright (C) 2014 by authors and Scientific Research Publishing Inc.

This work is licensed under the Creative Commons Attribution International License (CC BY). http://creativecommons.org/licenses/by/4.0/

(c) (i) 0pen Access

\begin{abstract}
Molybdenum phosphide (MoP) flakes were synthesized by the reduction of hexaammonium heptamolybdate tetrahydrate and ammonium dihydrogen phosphate. The flakes are porous and constructed by MoP nanoparticles with $c a .100 \mathrm{~nm}$ diameters. The lateral size of flakes ranges from less than $1 \mu \mathrm{m}$ to larger than $5 \mu \mathrm{m}$, and the thickness of MoP fakes is $c a .200 \mathrm{~nm}$. The mixture of MoP flakes and carbon black exhibits effective catalytic activity in the hydrogen evolution reaction. The optimal overpotential required for $20 \mathrm{~mA} \cdot \mathrm{cm}^{-2}$ current density is $155 \mathrm{mV}$ in acidic solution and $184 \mathrm{mV}$ in basic solution. The mixture can work stably in long-term hydrogen generation in both acidic and basic solution. The faradaic yield of mixture in hydrogen evolution reaction is nearly $\mathbf{1 0 0 \%}$ in both acidic and basic solution. The Mo and $P$ species in MoP flakes are found to have small positive and negative charge, respectively. The catalytic activity of MoP flakes is likely to be correlated with this charged nature.
\end{abstract}

\section{Keywords}

Molybdenum Phosphide, Hydrogen Evolution Reaction, Catalyst, Electrolysis

\section{Introduction}

As a clean and renewable resource, hydrogen is believed to be one of the most promising alternative energy carriers [1] [2]. Hydrogen can be generated by electrolysis or photoelectrolysis of water via the hydrogen evolution reaction (HER). Effective electrocatalysts for HER are essential for efficient hydrogen generation from electro-

${ }^{*}$ Corresponding author.

How to cite this paper: Chen, Z.Z., Lv, C.C., Chen, Z.B., Jin, L.H., Wang, J. and Huang, Z.P. (2014) Molybdenum Phosphide Flakes Catalyze Hydrogen Generation in Acidic and Basic Solutions. American Journal of Analytical Chemistry, 5, $1200-1213$. http://dx.doi.org/10.4236/ajac.2014.517127 
lysis and photoelectrolysis. Though platinum-group metals have shown excellent catalytic activity in HER, their widespread commercial application is inhibited by high cost and low abundance. The exploitation of effective and low-cost HER catalysts is therefore highly desirable.

Recently, the development of cost-effective HER catalysts has gained extensive attention. Great efforts have has been devoted to explore HER catalysts among transition metal chalcogenides (e.g., molybdenum sulfide [3]-[7], tungsten sulfide [8] [9], cobalt dichalcogenide [10] [11], iron dichalcogenide [10] [11], and nickel dichalcogenide [10] [11]), carbides (e.g., molybdenum carbide [12]-[14], and tungsten carbide [15] [16]), as well as nitrides and carbonitrides (e.g., molybdenum nitride [13], cobalt-molybdenum nitride [17], tungsten carbonitride [18]). On the other hand, nickel phosphide has been predicted to be an excellent catalyst in HER in 2005 [19], whereas the catalytic activity of nickel phosphide $\left(\mathrm{Ni}_{2} \mathrm{P}\right.$ nanoparticles) was experimentally confirmed in 2013 [20]. The successful demonstration of catalytic activity of $\mathrm{Ni}_{2} \mathrm{P}$ inspires research concerning the application of metal phosphide in hydrogen generation (e.g., $\mathrm{Ni}_{12} \mathrm{P}_{5}$ [21], and $\mathrm{CoP}$ [22] [23]).

Herein the catalytic activity of MoP flakes in HER is demonstrated. We found that MoP flakes show efficient catalytic activity in HER in both acidic and basic solution, and the corresponding overpotential required for 20 $\mathrm{mA} \cdot \mathrm{cm}^{-2}$ current density is $155 \mathrm{mV}$ in acidic solution and $184 \mathrm{mV}$ in basic solution, respectively. The performance is favorably comparable to most values of reported nonprecious metal catalysts. Potentiostatic electrolysis and accelerated degradation experiments demonstrate the long-term stability of MoP flakes in hydrogen generation in acidic and basic solution. The influence of synthesis temperature on catalytic activity of MoP flakes was revealed. Tafel slope suggests that the HER occuring on the surface of MoP flakes proceeds along Volmer-Heyrovsky mechanism. Mo and P in MoP flakes were found to have slight charge, and the catalytic activity of MoP might be correlated with these features.

\section{Experimental}

\subsection{Synthesis of MoP Flakes}

Hexaammonium heptamolybdate tetrahydrate $\left(\left(\mathrm{NH}_{4}\right)_{6} \mathrm{Mo}_{7} \mathrm{O}_{24} \cdot 4 \mathrm{H}_{2} \mathrm{O}, 0.9 \mathrm{~g}\right)$ and ammonium dihydrogen phosphate $\left(\mathrm{NH}_{4} \mathrm{H}_{2} \mathrm{PO}_{4}, 0.586 \mathrm{~g}\right)$ were dissolved in $100 \mathrm{~mL}$ deionized water, and the mixture was stirred at $90^{\circ} \mathrm{C}$ to evaporate all deionized water. The resulting dried powder was grinded in a mortar mixer, and then loaded in a quartz tube mounted in a tube furnace. The quartz tube was pumped to $20 \mathrm{~Pa}$ and filled with $5 \% \mathrm{H}_{2} / \mathrm{N}_{2}$. This procedure was repeated five times prior to heating to remove oxygen in the tube. After that, the temperature was increased to $800^{\circ} \mathrm{C}$ (heating rate: $3^{\circ} \mathrm{C} \cdot \mathrm{min}^{-1}$ ), and maintained at $800^{\circ} \mathrm{C}$ for $120 \mathrm{~min}$. During heating, the quartz tube was flowed with $5 \% \mathrm{H}_{2} / \mathrm{N}_{2}$ (flow rate: $100 \mathrm{sccm}$ ). After the reaction, the furnace was cooled naturally to room temperature.

\subsection{Characterization}

The structure of MoP flakes was investigated by X-ray diffraction (XRD) using a Bruker D8 Advance diffractometer with graphite-monochromated $\mathrm{Cu} \mathrm{K} \alpha$ radiation $(\lambda=1.54178 \AA$ ). The morphology of MoP flake was revealed by transmission electron microscopy (TEM) and scanning electron microscopy (SEM). TEM and SEM experiments were carried out on a JEM2100 (JEOL) and a JSM7001F (JEOL), respectively. The EDX spectra were recorded using an Oxford Instruments' INCA system equipped on the JSM7001F. For the TEM investigation, MoP flakes were dispersed in ethanol and then loaded onto a carbon-coated copper grid (300-mesh) by drop-coating. The X-ray photoelectron spectroscopy (XPS) experiments were carried out on an ESCALAB250Xi System (ThermoFisher) equipped with a monochromatic Al Ka $(1486.6 \mathrm{eV})$ source and a concentric hemispherical energy analyzer.

\subsection{Electrochemical Measurement}

All electrochemical measurements were carried out on a CHI 614D electrochemical workstation (CH Instrument) in a three-electrode electrochemical cell. A graphite rod (6 mm diameter) was used as counter electrode, and the counter electrode was separated from working chamber by porous glass frit. A mercury/mercurous sulfate electrode (MSE) or mercury/mercury oxide electrode (MMO) was used as reference electrode. The catalyst (4 mg), certain amount of carbon black (0, 2, 4, or $6 \mathrm{mg}$ ), and Nafion solution (5 wt\%, $80 \mu \mathrm{L}$ ) were dispersed in $1 \mathrm{ml}$ of water/ethanol (4/1, v/v) by ultrasonication (ultrasonic probe, $2 \mathrm{~mm}$ diameter, $130 \mathrm{~W}, 1 \mathrm{~h}$ ) to form homogeneous 
ink. Then different amounts of catalyst ink were loaded onto a glassy carbon electrode (3 mm diameter).

All solutions were purged with high purity $\mathrm{H}_{2}(99.999 \%)$ for $30 \mathrm{~min}$ prior to electrochemical measurements and during electrochemical measurements. The experiments carried out in $\mathrm{H}_{2} \mathrm{SO}_{4}$ solution $(0.5 \mathrm{M})$ used the MSE as reference electrode, and those in $\mathrm{KOH}(1 \mathrm{M})$ solution used the MMO. The reversible hydrogen evolution potential (RHE) was determined by the open circuit potential of a clean Pt electrode in the solution of interest bubbled with $\mathrm{H}_{2}$ (99.999\%), being $-0.694 \mathrm{~V}$ vs MSE for $0.5 \mathrm{M} \mathrm{H}_{2} \mathrm{SO}_{4}$ solution and $-0.876 \mathrm{~V}$ vs $\mathrm{MMO}$ for $1 \mathrm{M}$ $\mathrm{KOH}$ solution.

Polarization curves were measured at a sweep rate of $5 \mathrm{mV} \cdot \mathrm{s}^{-1}$ in rigorously stirred solution (1600 rpm). The uncompensated cell resistance (R) was determined by the current-interrupt method. Cyclic voltammetry (CV) sweep was carried out $50 \mathrm{mV} \cdot \mathrm{s}^{-1}$ sweep rate. Electrochemical impedance spectroscopy (EIS) measurements were carried out at different potentials in the frequency range $10^{-2}$ to $10^{6} \mathrm{~Hz}$ with $10 \mathrm{mV}$ sinusoidal perturbations and 12 steps per decade in $0.5 \mathrm{M} \mathrm{H}_{2} \mathrm{SO}_{4}$ solution.

The current and charge passing the circuit were measured with the electrochemical workstation and the voltage change of the MPXV7002DP was monitored with a digital multimeter (4 1/2 digits). Prior to experiment, the relationship between volume of gathered gas and the variation of output voltage of the MPXV7002DP (i.e., pressure variation in the gas gathering tube) was calibrated by injecting known amounts of air into the gas gathering tube and recording the variation of output voltage of the MPXV7002DP.

The volume of $\mathrm{H}_{2}$ during the potentiostatic electrolysis experiment was monitored by volume displacement method in a configuration shown in Figure 1. A Freescale MPXV7002DP differential pressure transducer was employed to monitor pressure variation in the gas gathering tube, and then the volume of generated $\mathrm{H}_{2}$ was computed from pressure variation in the gas gathering tube. If the initial height of water in the gas gathering tube before the gas gathering experiment is $\mathrm{h}_{0}$, and after the potentiostatic electrolysis experiment the generated gas is gathered into the tube and the final height of water in the gas gathering tube become $h_{1}$, then the volume of generated gas $(V)$ should be $s\left(h_{0}-h_{1}\right)$, where $s$ is the inner cross-sectional area of the gas gathering tube.

At the initial status, the pressure inside the gas gathering tube $\left(\mathrm{P}_{0}\right)$ is $\mathrm{P}-\rho \mathrm{gh}_{0}$, where $\mathrm{P}$ is the atmospheric pressure, is the density of water, and $\mathrm{g}$ is the acceleration due to gravity. The output voltage of the differential pressure transducer would be $\mathrm{U}_{0}=\mathrm{k}\left(\mathrm{P}-\mathrm{P}_{0}\right)=\mathrm{k} \rho \mathrm{gh}_{0}$, where $\mathrm{k}$ is the sensitivity of the differential pressure transducer ( $1 \mathrm{mV} / \mathrm{Pa}$ for a Freescale MPXV7002DP). When the height of water in the gas gathering tube decreases to $h_{1}$, the pressure inside the gas gathering tube becomes $\mathrm{P}_{1}$, and $\mathrm{P}_{1}=\mathrm{P}-\rho \mathrm{gh}_{1}$. Then, the output of the differential pressure transducer is $\mathrm{U}_{1}=\mathrm{k}\left(\mathrm{P}-\mathrm{P}_{1}\right)=\mathrm{k} \rho \mathrm{gh}_{1}$.

Accordingly, the volume of generated gas can be computed by

$\mathrm{V}=\mathrm{s}\left(\mathrm{h}_{0}-\mathrm{h}_{1}\right)=\mathrm{s}\left(\mathrm{U}_{0} / \mathrm{k} \rho \mathrm{g}-\mathrm{U}_{1} / \mathrm{k} \rho \mathrm{g}\right)=\mathrm{s}\left(\mathrm{U}_{0}-\mathrm{U}_{1}\right) / \mathrm{k} \rho \mathrm{g}=\mathrm{C}\left(\mathrm{U}_{0}-\mathrm{U}_{1}\right)$, where $\mathrm{C}$ is a coefficient that can be calibrated by injecting a known volume of gas into the gas gathering tube and recording the variation of output voltage of the differential pressure transducer.

\section{Results and Discussion}

MoP was synthesized by the reduction of hexaammonium heptamolybdate tetrahydrate $\left(\left(\mathrm{NH}_{4}\right)_{6} \mathrm{Mo}_{7} \mathrm{O}_{24} \cdot 4 \mathrm{H}_{2} \mathrm{O}\right)$ and ammonium dihydrogen phosphate $\left(\mathrm{NH}_{4} \mathrm{H}_{2} \mathrm{PO}_{4}\right)$ at $800^{\circ} \mathrm{C}$. The XRD pattern of product Figure 2(a) exhibits

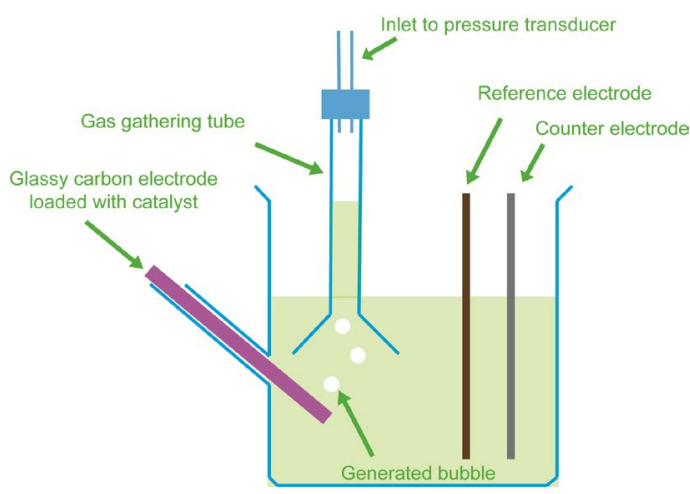

Figure 1. Illustration of the setup used to monitor the volume of generated gas. 

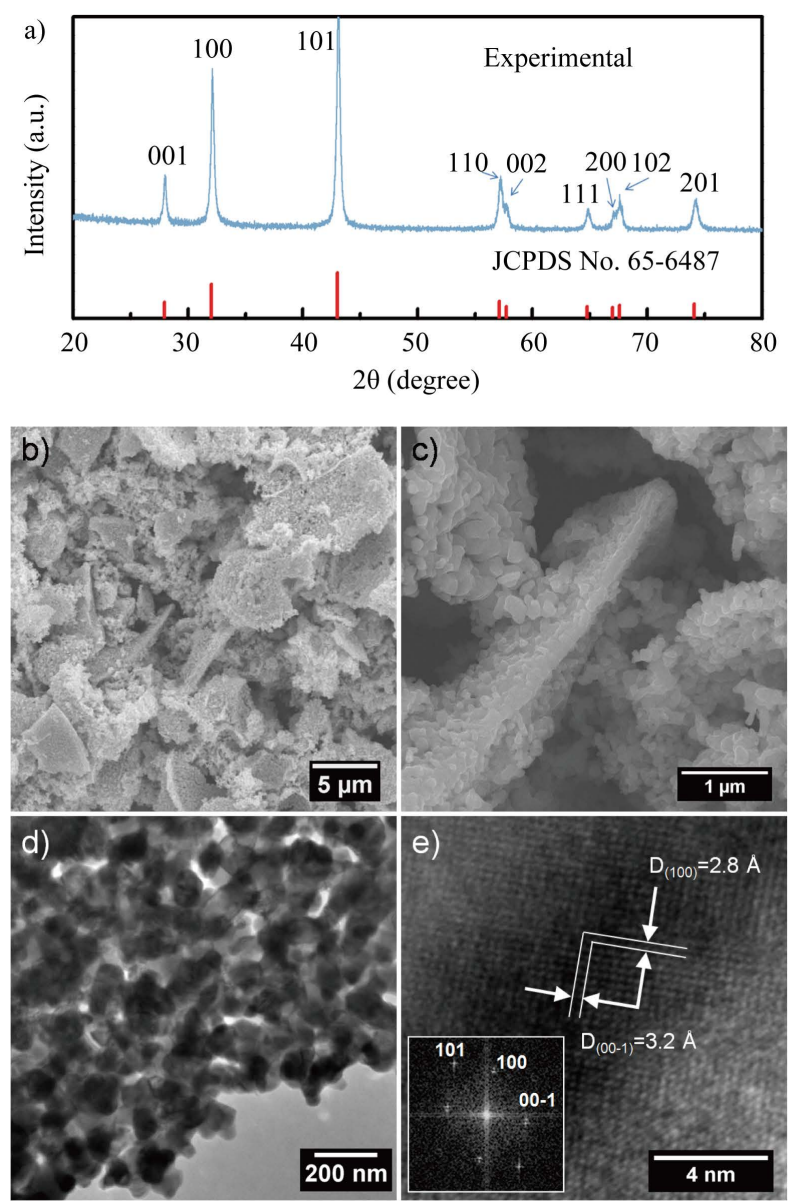

Figure 2. (a) XRD pattern of MoP. (b) Low and (c) high magnification SEM images of MoP flake. (d) TEM image of MoP flake. (e) HRTEM image of MoP flake.

distinct peaks, and these peaks can be assigned to those of hexagonal phase MoP (JCPDS No. 65-6487, $\mathrm{a}=$ $3.223 \AA, \mathrm{c}=3.191 \AA$ ). These distinct peaks suggest the good crystallinity of MoP. The composition information of product was accessed by EDX analysis carried out in SEM. The average atomic ratio of Mo to P recorded from five different sites is $0.976 \pm 0.053$ (Figure 3 and Table 1), in accordance with that of stoichiometrical MoP (1:1).

Typical morphology of MoP was investigated by SEM and TEM. Figure 2(b) shows the low magnification SEM image of MoP, revealing a flake like morphology. The lateral size of MoP flakes ranges from less than $1 \mu \mathrm{m}$ to larger than $5 \mu \mathrm{m}$, and the thickness of MoP fakes is $c a .200 \mathrm{~nm}$ (Figure 2(c)). It is further revealed that the MoP flakes are porous and constructed by MoP nanoparticles with diameter $c a .100 \mathrm{~nm}$ (Figure 4(d)). The high-resolution TEM (HRTEM) image suggests that these small MoP nanoparticles are single crystalline (Figure 4(e)). The good crystallinity of the MoP nanoparticles can be suggested by the well defined lattice fringes. The distances between fringes are measured to be 2.8 and $3.2 \AA$, respectively, corresponding well to those between the (100) and (00-1) planes of hexagonal phase MoP. The pattern resulted from fast Fourier transform (FFT) of the lattice fringes is shown in the inset of Figure 2(e), matching well that of the (010) zone axis diffraction pattern of hexagonal phase MoP.

The MoP flakes exhibit effective catalytic activity in HER. Linear sweep voltammetry (LSV) experiments were carried out to obtain polarization curves of MoP flakes. Figure 4 shows the optimal performance of MoP flake loaded on glassy carbon electrode (GCE) with and without addition carbon black (Vulcan XC-72R). For comparison, the polarization curves of bare GCE and GCE loaded with carbon black (C on GCE) are also shown. It is found that in acidic solution $\left(\mathrm{H}_{2} \mathrm{SO}_{4}, 0.5 \mathrm{M}\right)$ overpotential required for current density of $10 \mathrm{~mA} \cdot \mathrm{cm}^{-2}\left(\eta_{10}\right)$ 


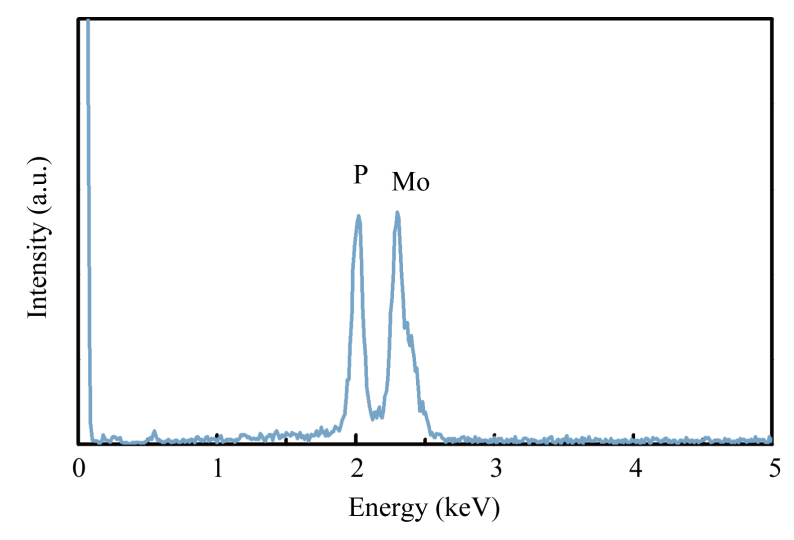

Figure 3. Typical EDX spectrum recorded from MoP in SEM.

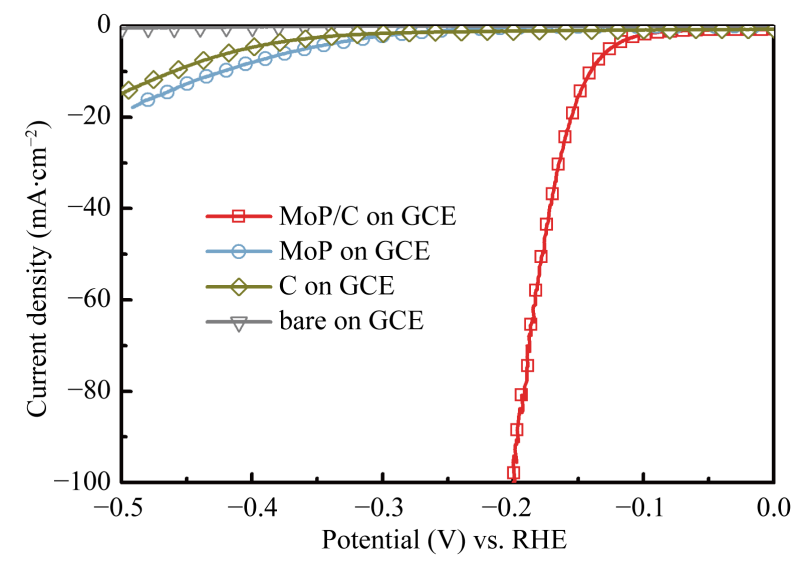

Figure 4. Polarization curves of MoP/C on GCE (loading amount: $1.425 \mathrm{mg} \cdot \mathrm{cm}^{-2}$ of MoP and $0.7125 \mathrm{mg} \cdot \mathrm{cm}^{-2}$ of C), MoP on GCE (loading amount: $0.855 \mathrm{mg} \cdot \mathrm{cm}^{-2}$ ), C on GCE (loading amount: $0.7125 \mathrm{mg} \cdot \mathrm{cm}^{-2}$ ), and bare GCE. Potentials are corrected with iR drop.

Table 1. Atomic ratio of Mo to P determined by EDX experiments in SEM.

\begin{tabular}{ccccccc}
\hline & 1 & 2 & 3 & 4 & 5 & Average \\
\hline Mo:P & 0.923 & 1.05 & 0.938 & 0.958 & 1.01 & $0.976 \pm 0.053$ \\
\hline
\end{tabular}

for MoP on GCE is $c a$. $423 \mathrm{mV}$, while $\eta_{10}$ is markedly reduced to $141 \mathrm{mV}$ and $\eta_{20}$ (overpotential required for current density of $20 \mathrm{~mA} \cdot \mathrm{cm}^{-2}$ ) is as small as $155 \mathrm{mV}$ for the hybrid materials of MoP flakes and carbon black (MoP/C on GCE). The current density of carbon black on GCE (C on GCE) is smaller than that of MoP on GCE, and bare GCE shows neglectable current density in the potential range of $-0.5-0 \mathrm{~V}$ vs RHE, suggesting that the current in MoP/C on GCE sample can be associated with MoP flakes. The small current density in MoP on GCE sample might be correlated with slow electron transport between less-conducting MoP flakes. The introduction of carbon black enables rapid electron transport from electrode to MoP flakes at catalyst/electrolyte interface, and results in markedly enhanced hydrogen generation performance.

The $\eta_{10}$ and $\eta_{20}$ are usually adopted as key parameters for the comparison of the catalytic activity of different HER catalysts, because the typical current density of photoelectrochemical water splitting cell ranges in 10 - 20 $\mathrm{mA} \cdot \mathrm{cm}^{-2}$ under the solar photon flux of 1 Sun AM 1.5 illumination [24]. Typical $\eta_{10}$ and $\eta_{20}$ of nonprecious HER catalysts are listed in Table 2 . It is shown that the optimal $\eta_{10}$ and $\eta_{20}$ of MoP/C on GCE are favorably comparable to most values of reported nonprecious metal HER catalyst.

The HER performance depends heavily on the loading amount of MoP flake and carbon black. A series of 
Table 2. Summary of HER performance of representative catalysts.

\begin{tabular}{|c|c|c|c|c|c|}
\hline Catalyst & Substrate & Mass density $\left(\mathrm{mg} / \mathrm{cm}^{2}\right)$ & $\eta_{10}^{\mathrm{b}}(\mathrm{mV})$ & $\eta_{20}{ }^{\mathrm{c}}(\mathrm{mV})$ & Electrolyte \\
\hline Amorphous $\mathrm{MoS}_{3}-\mathrm{CV}$ [7] & GCE & & 211 & 229 & $1 \mathrm{M} \mathrm{H}_{2} \mathrm{SO}_{4}$ \\
\hline $\mathrm{WS}_{2}$ nanosheets [8] & GCE & 0.285 & 151 & 177 & $1 \mathrm{M} \mathrm{H}_{2} \mathrm{SO}_{4}$ \\
\hline $\mathrm{WS}_{2}$ nanosheets [9] & GCE & $\begin{array}{c}0.0001-0.0002 \text { or } \\
c a \text {. one continuous layer }\end{array}$ & 233 & 275 & $0.5 \mathrm{M} \mathrm{H}_{2} \mathrm{SO}_{4}$ \\
\hline $\mathrm{FeSe}_{2}[11]$ & GCE & & & & $0.5 \mathrm{M} \mathrm{H}_{2} \mathrm{SO}_{4}$ \\
\hline $\mathrm{CoS}_{2}[11]$ & GCE & & 232 & & $0.5 \mathrm{M} \mathrm{H}_{2} \mathrm{SO}_{4}$ \\
\hline $\mathrm{Fe}_{0.43} \mathrm{Co}_{0.57} \mathrm{~S}_{2}[11]$ & GCE & & 264 & & $0.5 \mathrm{M} \mathrm{H}_{2} \mathrm{SO}_{4}$ \\
\hline $\mathrm{CoSe}_{2}[11]$ & GCE & 0.037 & 231 & & $0.5 \mathrm{M} \mathrm{H}_{2} \mathrm{SO}_{4}$ \\
\hline $\mathrm{Co}_{0.56} \mathrm{Ni}_{0.44} \mathrm{Se}_{2}[11]$ & GCE & & 250 & & $0.5 \mathrm{M} \mathrm{H}_{2} \mathrm{SO}_{4}$ \\
\hline $\mathrm{Co}_{0.32} \mathrm{Ni}_{0.68} \mathrm{~S}_{2}[11]$ & GCE & & & & $0.5 \mathrm{M} \mathrm{H}_{2} \mathrm{SO}_{4}$ \\
\hline $\mathrm{NiS}_{2}[11]$ & GCE & & & & $0.5 \mathrm{M} \mathrm{H}_{2} \mathrm{SO}_{4}$ \\
\hline $\mathrm{NiSe}_{2}[11]$ & GCE & & 250 & & $0.5 \mathrm{M} \mathrm{H}_{2} \mathrm{SO}_{4}$ \\
\hline Bulk $\mathrm{Mo}_{2} \mathrm{C}[12]$ & Carbon paste electrode & 1.4 & 208 & 224 & $0.50 \mathrm{M} \mathrm{H}_{2} \mathrm{SO}_{4}$ \\
\hline Bulk MoB [12] & Carbon paste electrode & 2.5 & 212 & 227 & $0.50 \mathrm{M} \mathrm{H}_{2} \mathrm{SO}_{4}$ \\
\hline $\mathrm{Mo}_{1}$ Soy [13] & Carbon paper & 1.4 & 177 & & $0.1 \mathrm{M} \mathrm{HClO}_{4}$ \\
\hline $\mathrm{Mo}_{1}$ Soy-RGO [13] & Carbon paper & 0.47 & 109 & & $0.1 \mathrm{M} \mathrm{HClO}_{4}$ \\
\hline $\mathrm{Mo}_{2} \mathrm{C} / \mathrm{C}[13]$ & Carbon paper & 2 & 311 & & $0.1 \mathrm{M} \mathrm{HClO}_{4}$ \\
\hline $\mathrm{Mo}_{2} \mathrm{C} / \mathrm{CNT}[14]$ & Carbon paper & 2 & 149 & & $0.1 \mathrm{M} \mathrm{HClO}_{4}$ \\
\hline Fe-WCN [16] & RRDE & 0.4 & 220 & & $\begin{array}{l}\mathrm{H}_{2} \mathrm{SO}_{4}(\mathrm{pH} 1)+ \\
\mathrm{Na}_{2} \mathrm{SO}_{4}(0.5 \mathrm{M})\end{array}$ \\
\hline $\mathrm{Co}_{0.6} \mathrm{Mo}_{1.4} \mathrm{~N}_{2}[17]$ & GCE & 0.243 & 202 & 267 & $0.1 \mathrm{M} \mathrm{HClO}_{4}$ \\
\hline $\mathrm{FeS}_{2}[18]$ & GCE & & 192.6 & & $0.5 \mathrm{M} \mathrm{H}_{2} \mathrm{SO}_{4}$ \\
\hline $\mathrm{Ni}_{2} \mathrm{P}[20]$ & Ti foil & 1 & 117 & 130 & $0.50 \mathrm{M} \mathrm{H}_{2} \mathrm{SO}_{4}$ \\
\hline $\mathrm{Ni}_{12} \mathrm{P}_{5}[21]$ & Ti foil & 3 & & 143 & $0.50 \mathrm{M} \mathrm{H}_{2} \mathrm{SO}_{4}$ \\
\hline CoP/CNT [22] & GCE & 0.285 & 122 & & $0.50 \mathrm{M} \mathrm{H}_{2} \mathrm{SO}_{4}$ \\
\hline CoP [23] & Ti foil & 2 & & 85 & $0.50 \mathrm{M} \mathrm{H}_{2} \mathrm{SO}_{4}$ \\
\hline $\mathrm{CoP}[30]$ & carbon cloth & 0.92 & 67 & 100 & $0.50 \mathrm{M} \mathrm{H}_{2} \mathrm{SO}_{4}$ \\
\hline Ni-Mo nanopowder [31] & Ti foil & 1 & & 70 & $2 \mathrm{M} \mathrm{NaOH}$ \\
\hline Ni-Mo nanopowder [31] & Ti foil & 3 & & 80 & $0.5 \mathrm{M} \mathrm{H}_{2} \mathrm{SO}_{4}$ \\
\hline Ni-Mo nanopowder [31] & Ti foil & 1 & 79 & 107 & $1 \mathrm{M} \mathrm{NaOH}$ \\
\hline $\mathrm{MoS}_{3}(33 \%) / \mathrm{MWCNT}-\mathrm{NC}$ [32] & Silver electrode & 0.255 & 206 & 226 & $1 \mathrm{M} \mathrm{H}_{2} \mathrm{SO}_{4}$ \\
\hline $\begin{array}{c}\text { Core-shell } \mathrm{MoO}_{3}-\mathrm{MoS}_{2} \\
\text { nanowires [33] }\end{array}$ & FTO & & 254 & 272 & $0.5 \mathrm{M} \mathrm{H}_{2} \mathrm{SO}_{4}$ \\
\hline $\begin{array}{l}\text { Defect-rich } \mathrm{MoS}_{2} \text { nanosheets } \\
{[34]}\end{array}$ & GCE & 0.285 & 190 & 214 & $0.5 \mathrm{M} \mathrm{H}_{2} \mathrm{SO}_{4}$ \\
\hline $\mathrm{MoS}_{2} @ \mathrm{Au}[35]$ & Au electrode & 0.00103 & 226 & & $0.5 \mathrm{M} \mathrm{H}_{2} \mathrm{SO}_{4}$ \\
\hline $\mathrm{MoS}_{2} /$ RGO hybrid [36] & GCE & 0.285 & 154 & 176 & $0.5 \mathrm{M} \mathrm{H}_{2} \mathrm{SO}_{4}$ \\
\hline $\mathrm{MoS}_{2} / \mathrm{MGF}[37]$ & GCE & 0.21 & 146 & 159 & $0.5 \mathrm{M} \mathrm{H}_{2} \mathrm{SO}_{4}$ \\
\hline $\mathrm{MoS}_{2} / \mathrm{CNTs}[38]$ & Glass carbon disk & 0.136 & 184 & 230 & $0.5 \mathrm{M} \mathrm{H}_{2} \mathrm{SO}_{4}$ \\
\hline $\mathrm{Cu}_{2} \mathrm{MoS}_{4}[39]$ & GCE & 0.0425 & 321 & & $\mathrm{pH} 0 \mathrm{H}_{2} \mathrm{SO}_{4}$ \\
\hline $\mathrm{WS}_{2} / \mathrm{RGO}[40]$ & GCE & 0.4 & 265 & 292 & $0.5 \mathrm{M} \mathrm{H}_{2} \mathrm{SO}_{4}$ \\
\hline Cobalt-sulfide catalyst [41] & FTO & & 165 & 227 & $1.0 \mathrm{M} \mathrm{pH} 7 \mathrm{PBS}$ \\
\hline $\mathrm{NiWS}_{\mathrm{x}}[41]$ & FTO & & 373 & 430 & pH 7 PBS \\
\hline $\mathrm{CoWS}_{\mathrm{x}}[41]$ & FTO & & 271 & 311 & pH 7 PBS \\
\hline $\mathrm{CoMoS}_{\mathrm{x}}[41]$ & FTO & & 241 & 282 & pH 7 PBS \\
\hline
\end{tabular}

${ }^{\mathrm{a}} \eta_{10}$ : overpotential required for $10 \mathrm{~mA} \cdot \mathrm{cm}^{-2}$ current density; ${ }^{\mathrm{b}} \eta_{20}$ : overpotential required for $20 \mathrm{~mA} \cdot \mathrm{cm}^{-2}$ current density. 
LSV experiments were carried out to determine the optimal performance of MoP flake. These results are shown in Figure 5. The $\eta_{10}$ of MoP on GCE sample firstly increases with the loading amount of MoP, with the optimal loading amount of $0.855 \mathrm{mg} \cdot \mathrm{cm}^{-2}$, and further increase the loading amount of MoP results in the decreasing of $\eta_{10}$. The relationships between $\eta_{20}$ and the loading amount of MoP in MoP/C on GCE samples with different weight ratios of MoP to C are summarized (Figure 5(b)), and the corresponding polarization curves are shown in panels c-e of Figure 5. It is shown that the smallest $\eta_{20}$ can be found in MoP/C on GCE with the weight

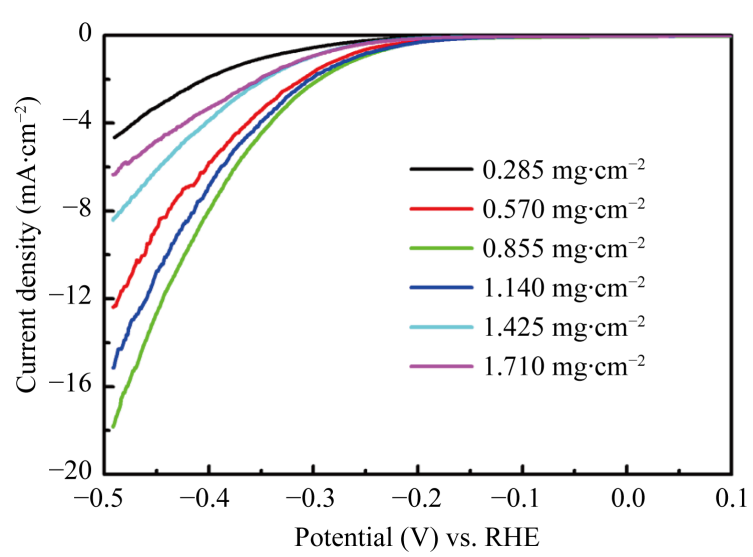

(a)

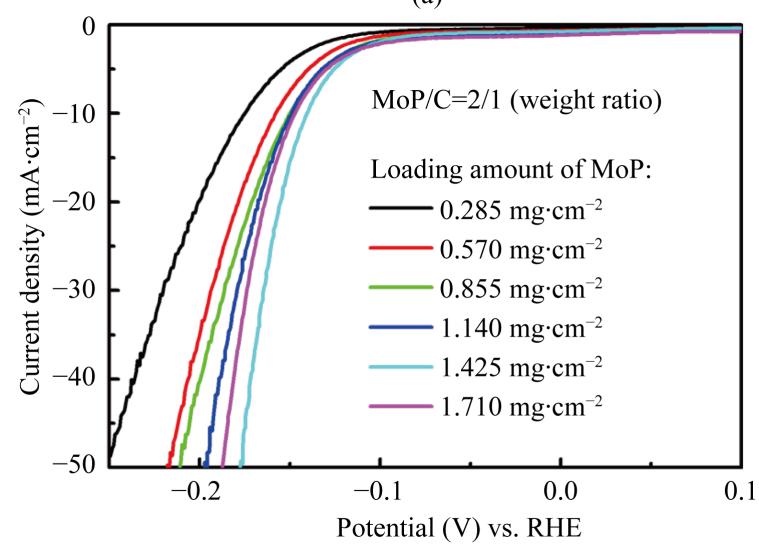

(c)

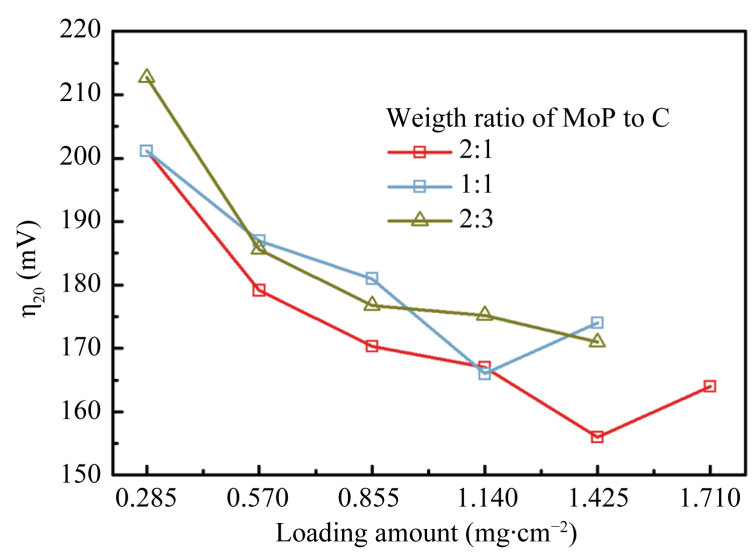

(b)

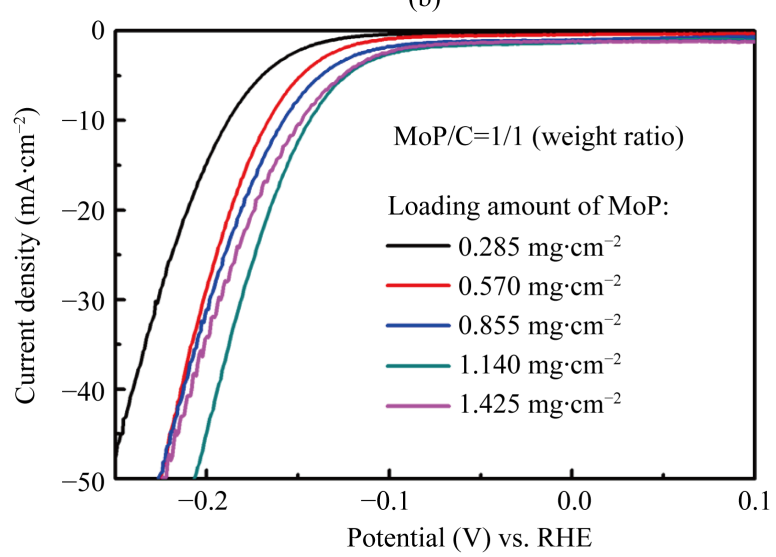

(d)

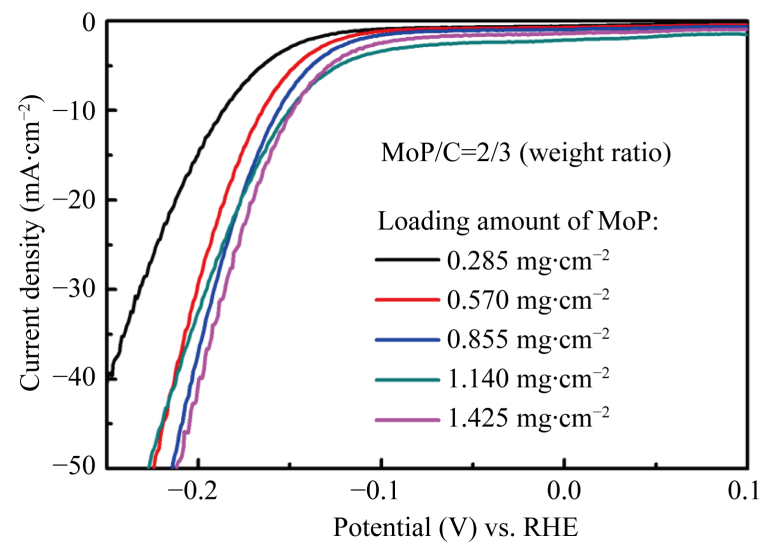

(e)

Figure 5. (a) Polarization curves of GCE loaded with different amount of MoP flake. (b) The relationship between $\eta_{20}$ and loading amount of MoP in MoP/C on GCE. Different weight ratios of MoP to C have been evaluated to find the optimal $\eta_{20}$. The polarization curves of MoP/C on GCE for different weight ratio of MoP to C: (c) 2/1, (d) 1/1, and (e) 2/3. Potentials were corrected with iR drop. 
ratio of MoP to C being 2:1 and the loading amount of MoP being $1.425 \mathrm{mg} \cdot \mathrm{cm}^{-2}$.

The fabrication temperature influences the catalytic activity of MoP flake in HER. MoP flakes were fabricated at different temperatures, and the products are denoted as MoPxxx, where xxx is the fabrication temperature. The plots of $\eta_{20}$ versus the loading amounts of MoP750 and MoP850 are shown in Figure 6(a), and the polarization curves of MoP750, and MoP850 can be found in Figure 6(b) and Figure 6(c), respectively. The optimal $\eta_{20}$ is $210 \mathrm{mV}$ for M750 (the loading amount of MoP: $1.425 \mathrm{mg} \cdot \mathrm{cm}^{-2}$ ) and $190 \mathrm{mV}$ for M850 (the loading amount of MoP: $1.425 \mathrm{mg} \cdot \mathrm{cm}^{-2}$ ), respectively, both larger than that of MoP800 (Figure 4). The XRD experiments reveal that the structure of M750 and M850 is the same as that of MoP800 (Figure 7(a)), and no impurity phase can be detected from the corresponding XRD patterns. The peaks are more distinct for sample obtained at higher temperature, suggesting that higher temperature would be beneficial for the crystallization of MoP flake. The specific surface areas of MoP750, MoP800, and MoP850 were measured by Brunauer, Emmett and Teller (BET) method Figure 7(b), being 4.798, 4.835, and $3.767 \mathrm{~m}^{2} \cdot \mathrm{g}^{-1}$, respectively. The results of XRD and BET experiments suggest that the crystallinity and surface area of MoP flake work cooperatively, resulting in an optimal catalytic activity of sample obtained at $800^{\circ} \mathrm{C}$.

The faradaic efficiency of MoP flakes in HER was evaluated by the comparison of measured volume and theoretical volume of generated hydrogen. The generated hydrogen was measured by water displacement method, and the theoretical volume was computed by assuming that all elecrons passing through the circuit are consumed by the reduction reaction of $\mathrm{H}^{+}\left(2 \mathrm{H}^{+}+2 \mathrm{e}^{-} \rightarrow \mathrm{H}_{2}\right)$. Figure 8 shows the plots of measured volume and theoretical volume of hydrogen generated during a potentiostatic electrolysis. The measured volume of hydrogen matches well the theoretical one within experimental error, suggesting that the faradaic efficiency of MoP flakes is nearly $100 \%$ in hydrogen generation.

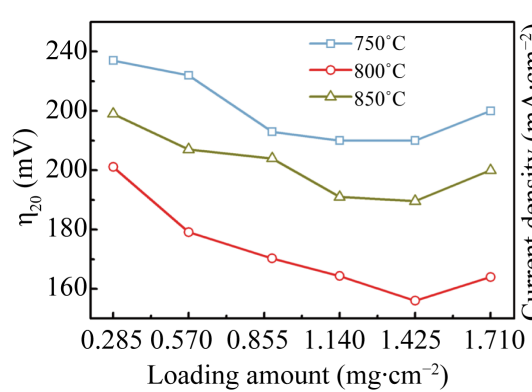

(a)

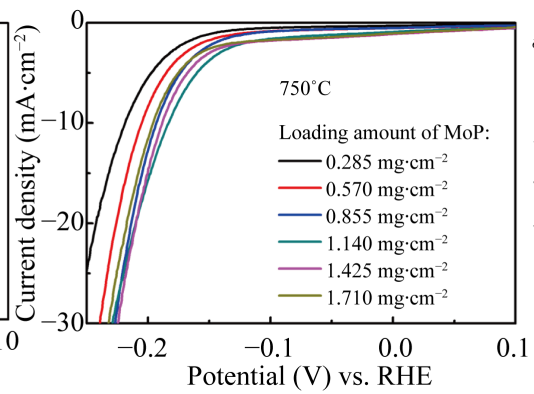

(b)

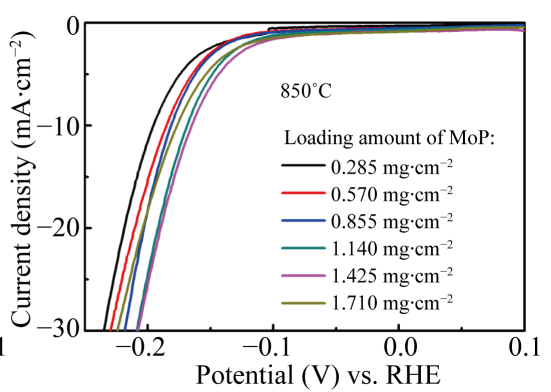

(c)

Figure 6. (a) The relationship between $\eta_{20}$ and loading amount of MoP in MoP/C on GCE for MoP fabricated at different temperatures. Polarization curves of MoP fabricated at (b) $750^{\circ} \mathrm{C}$ and (c) $850^{\circ} \mathrm{C}$. The weight ratio of MoP to C is kept as $2: 1$. Potentials were corrected with iR drop.

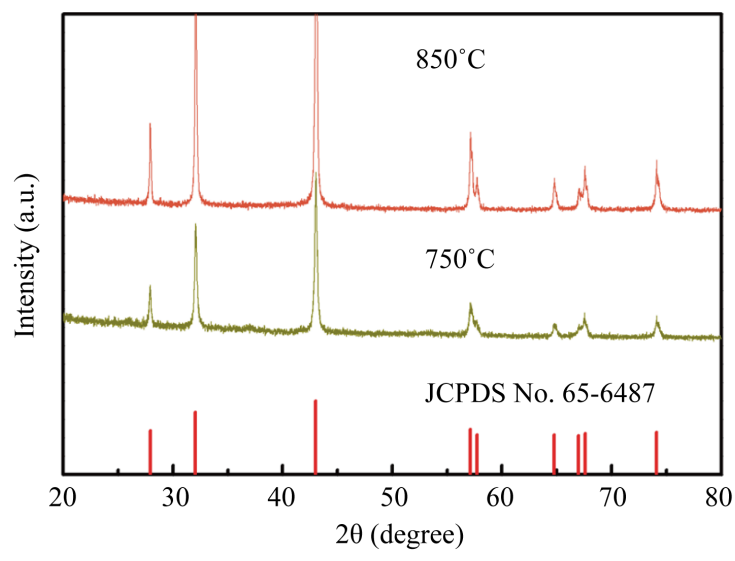

(a)

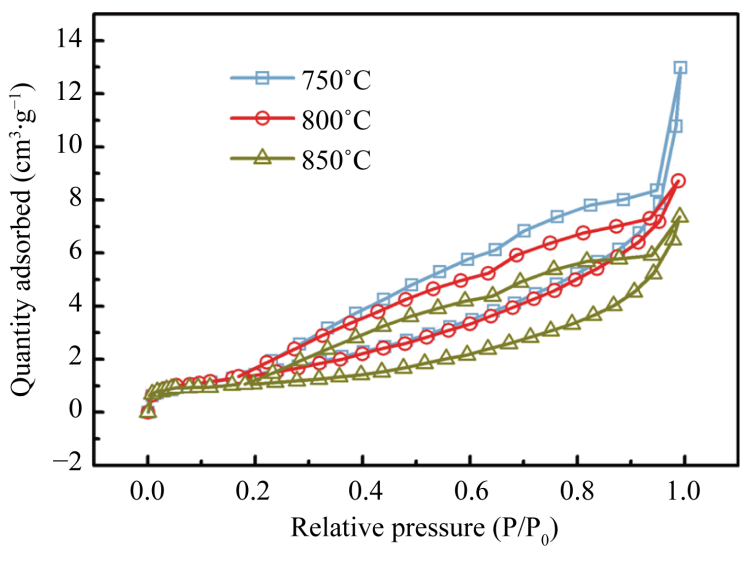

(b)

Figure 7. (a) XRD patterns of products obtained at different temperatures. (b) Nitrogen adsorption/desorption isotherm of MoP obtained at different temperatures. 


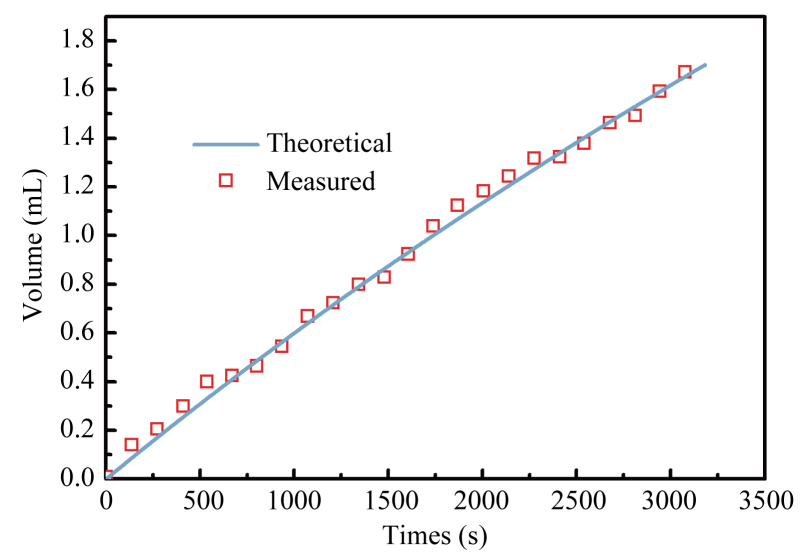

Figure 8. Plots of theoretical and measured volume of generated hydrogen in a potentiostatic electrolysis experiment. The sample is MoP/C on GCE (loading amount: $1.425 \mathrm{mg} \cdot \mathrm{cm}^{-2}$ of $\mathrm{MoP}$ and $0.7125 \mathrm{mg} \cdot \mathrm{cm}^{-2}$ of $\mathrm{C}$ ), and applied potential is -0.25 $\mathrm{V}$ vs RHE (without iR correction).

Long-term stability during hydrogen generation is also important for the practical application of HER catalyst. MoP flake was found to work stably in acidic solution during hydrogen generation, as indicated by potentiostatic electrolysis and accelerated degradation experiments (Figure 9). A potentiostatic electrolysis experiment shows that only slightly decrease of current density occurs in the first $5000 \mathrm{~s}$, and thereafter the current density is nearly unchanged. An accelerated degradation experiment was carried out by repeated cyclic voltammetry (CV) sweep. Negligible difference can be found between the polarization curves of the initial and 2000th scan. The potentiostatic electrolysis and accelerated degradation experiments demonstrate the long-term hydrogen generation capability of MoP flakes.

To obtain insight into the HER process of MoP flakes, EIS experiments were carried out in acidic solution. The spectra corresponding to different applied potentials are shown in a Nyquist plot in Figure 10(a). All spectra contain two semicircles, and they can be well fitted with a two-time-constant equivalent circuit (Figure 11). Charge transfer resistance $\left(\mathrm{R}_{\mathrm{ct}}\right)$ at solid/liquid interface was derived from semicircles at low frequencies range. $\mathrm{R}_{\mathrm{ct}}$ is associated with HER kinetics of a catalyst, and a smaller $\mathrm{R}_{\mathrm{ct}}$ suggests faster kinetics. Figure 10(a) shows that $R_{c t}$ decreases with increasing applied potential, in accordance with larger current density at larger applied potential. The applied potentials are plotted versus inverse $\mathrm{R}_{\mathrm{ct}}$ on a logarithmic scale (Figure 10(b)), and the Tafel slope was determined by the slope in the plot, being $71.77 \mathrm{mV} \cdot \mathrm{dec}^{-1}$.

The HER process can be revealed by Tafel slope. In general, a classic two-electron-reaction model suggests that the HER process can proceed in two steps: a discharge step (Volmer reaction: $\mathrm{H}_{3} \mathrm{O}^{+}+\mathrm{e}^{-} \rightarrow \mathrm{H}_{\text {ads }}+\mathrm{H}_{2} \mathrm{O}$ ) followed by a desorption step (Heyrovsky reaction: $\mathrm{H}_{\mathrm{ads}}+\mathrm{H}_{3} \mathrm{O}^{+}+\mathrm{e}^{-} \rightarrow \mathrm{H}_{2}+\mathrm{H}_{2} \mathrm{O}$ ), or a discharge step followed by a recombination step (Tafel reaction: $\mathrm{H}_{\mathrm{ads}}+\mathrm{H}_{\mathrm{ads}} \rightarrow \mathrm{H}_{2}$ ), where $\mathrm{H}_{\text {ads }}$ represents a $\mathrm{H}$ atom absorbed at the active site of the catalyst. The rate-limiting step can be identified by Tafel analysis of the catalyst, and a Tafel slope of 116, 38, or $29 \mathrm{mV} \cdot \mathrm{dec}^{-1}$ assigns the rate-determining step in the HER process to Volmer, Heyrovsky, or Tafel reaction. The Tafel slope of $71.77 \mathrm{mV} \cdot \mathrm{dec}^{-1}$ lies between 38 and $116 \mathrm{mV} \cdot \mathrm{dec}^{-1}$, suggesting that a VolmerHeyrovsky mechanism might be responsible for the HER process [13], and that the rates of the discharge step and the desorption step might be comparable during the HER process [25].

The chemical states of Mo and P in MoP flake were investigated by XPS experiments to find possible origin of the HER catalytic activity of MoP flake. The corresponding results are shown in Figure 12. The XPS spectrum of the Mo 3d window can be fitted to two doublets with peaking energy at $228.3 \mathrm{eV}$ and $232.5 \mathrm{eV}$, respectively Figure 12(a). The peak at $228.3 \mathrm{eV}$ can be associated with Mo in MoP [26] [27], and this binding energy is very close to that of elemental Mo $(227.9 \mathrm{eV})$ [28], implying that these Mo species have very a small positive charge. On the other hand, the peak at $232.5 \mathrm{eV}$ suggests the presence of $\mathrm{Mo}^{6+}$ species in product [26] [27]. Two doublets (129.5 and $133.8 \mathrm{eV}$ ) can be found in the P 2p window Figure 12(b). The doublet at $129.5 \mathrm{eV}$ can be attributed to P bonding to Mo [26] [27], and these P species have a slightly negative charge, because their binding energy $(129.5 \mathrm{eV})$ is only $0.5 \mathrm{eV}$ smaller than that of elemental $\mathrm{P}(130.0 \mathrm{eV})$ [29]. The doublet at $133.8 \mathrm{eV}$ 


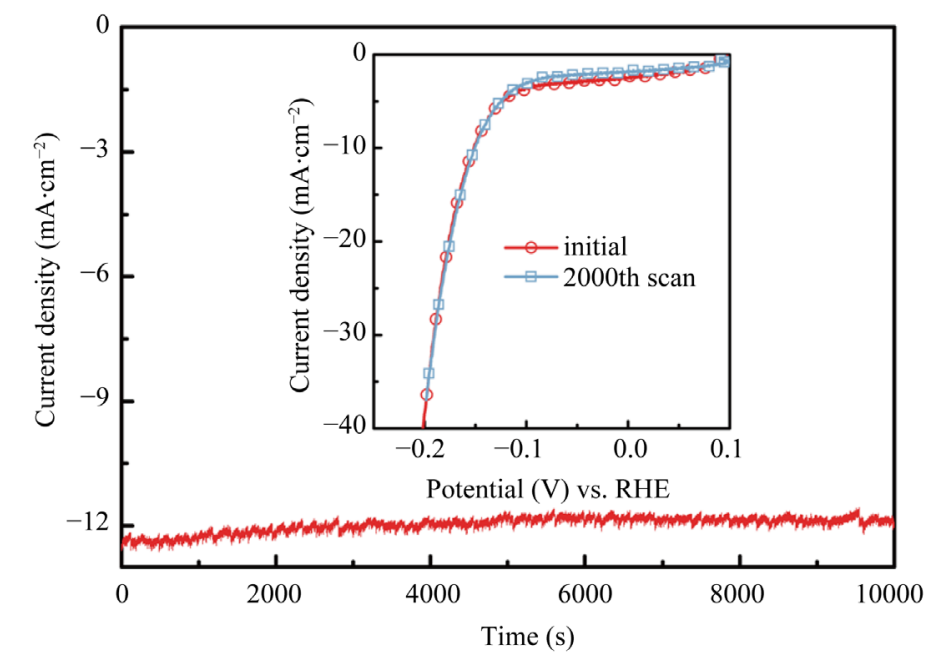

Figure 9. Relationship of current density and experimental time in potentiostatic experiment (applied potential: $-0.15 \mathrm{~V}$ vs RHE). Inset shows the polarization curves corresponding to the initial and 2000th scan in CV sweep. The sample is MoP/C on GCE (loading amount: $1.425 \mathrm{mg} \cdot \mathrm{cm}^{-2}$ of $\mathrm{MoP}$ and $0.7125 \mathrm{mg} \cdot \mathrm{cm}^{-2}$ of $\mathrm{C}$ ), and potentials were not corrected with $\mathrm{iR}$ drop.

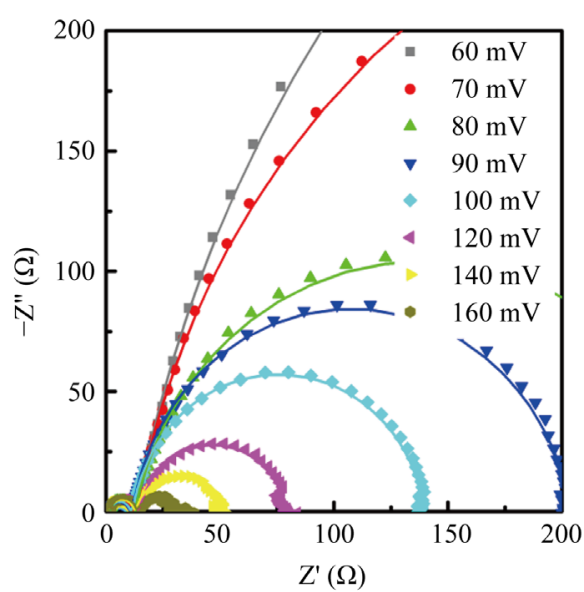

(a)

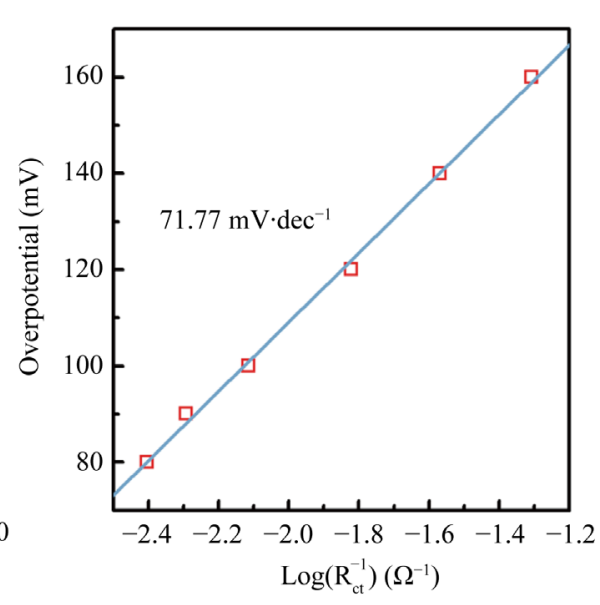

(b)

Figure 10. (a) Nyquist plot of EIS spectra at different overpotential recorded from MoP/C on GCE sample. (b) Plot of overpotential and inverse $\mathrm{R}_{\mathrm{ct}}$ on a logarithmic scale. The sample is $\mathrm{MoP} / \mathrm{C}$ on GCE (loading amount: $1.425 \mathrm{mg} \cdot \mathrm{cm}^{-2}$ of MoP and $0.7125 \mathrm{mg} \cdot \mathrm{cm}^{-2}$ of C), and potentials were not iR corrected.

can be related to $\mathrm{P}$ in $\mathrm{PO}_{4}^{3-}$ species [26] [27]. The $\mathrm{Mo}^{6+}$ and $\mathrm{PO}_{4}^{3-}$ possibly come from un-reacted precursor or oxidation product of $\mathrm{MoP}$ due to air exposure.

In $\mathrm{Mo}_{2} \mathrm{C}$ and $\mathrm{Mo}_{2} \mathrm{~N}$, Mo was found to have very small positive charge because of charge transfer from Mo to $\mathrm{C}$ or $\mathrm{N}$ [13] [14]. The d band electron structure becomes similar to that of Pt as a result of the charge transfer, and the HER catalytic activity of $\mathrm{Mo}_{2} \mathrm{C}$ and $\mathrm{Mo}_{2} \mathrm{~N}$ have been associated with the modified $\mathrm{d}$ band structure of Mo [14]. The XPS spectrum of the Mo 3d window from MoP flakes reveals that Mo species in MoP flakes also have a very small positive charge. In addition, active sites in hydrogenase [19], its analogues (Ni(PS3 $\left.\left.{ }^{*}\right)(\mathrm{CO})\right]^{-}$ and $\left.\left[\mathrm{Ni}(\mathrm{PNP})_{2}\right]^{2+}\right)$ [19] and $\mathrm{Ni}_{2} \mathrm{P}$ [19] contain hydride acceptors (Ni), which have a small positive charge. The charged nature of Mo in MoP resembles that of $\mathrm{Mo}$ in $\mathrm{Mo}_{2} \mathrm{C}$ and $\mathrm{Mo}_{2} \mathrm{~N}$, as well as the hydride acceptors in hydrogenase, its analogues, and $\mathrm{Ni}_{2} \mathrm{P}$, implying that the weakly charged Mo species in MoP might contribute to the catalytic activity of MoP. On the other hand, the proton acceptors are another kind of active sites in hydrogenase, 


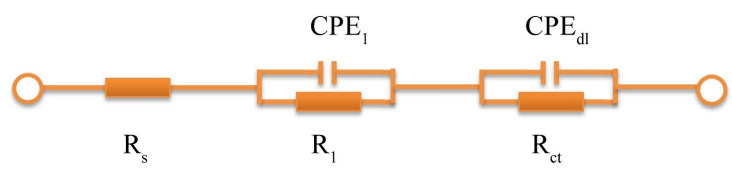

Figure 11. Equivalent circuit used for fitting of EIS data. $R_{s}$ is the overall series resistance, $\mathrm{CPE}_{1}$ and $\mathrm{R}_{1}$ are the constant phase element and resistance describing electron transport at MoP/C and GCE interface or between MoP/C, respectively, $\mathrm{CPE}_{\mathrm{dl}}$ is the constant phase element of the MoP/electrolyte interface, and $\mathrm{R}_{\mathrm{ct}}$ is the charge transfer resistance at $\mathrm{MoP} / \mathrm{electrolyte}$ interface.

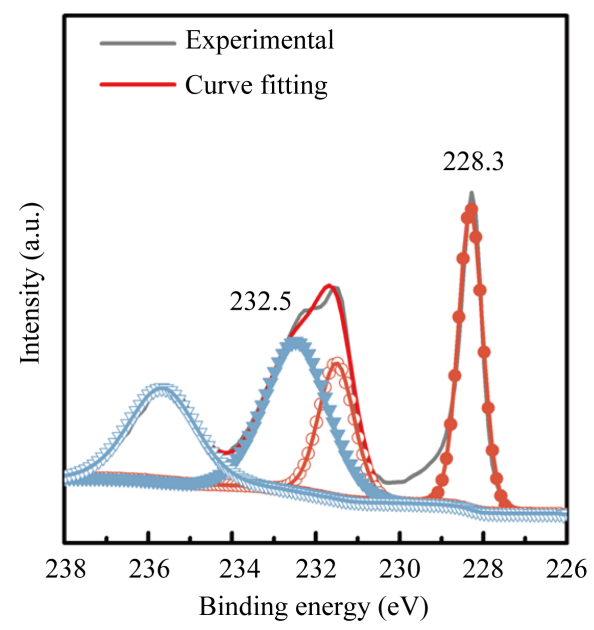

(a)

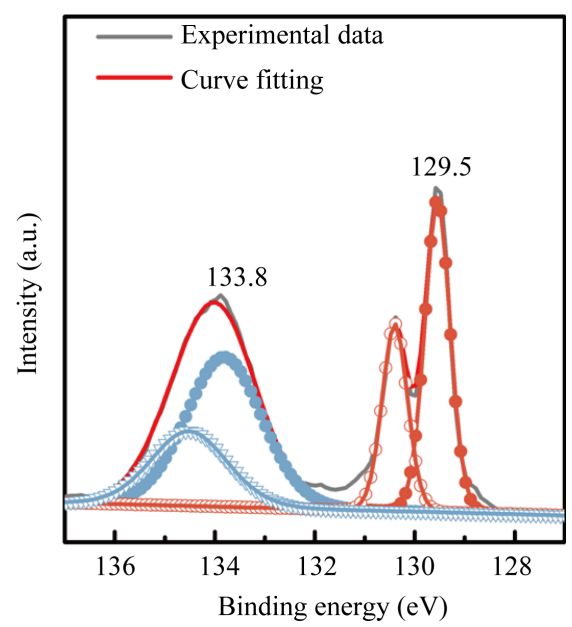

(b)

Figure 12. XPS spectra of (a) Mo 3d window and (b) P 2p window collected from MoP flake.

its analogues, and $\mathrm{Ni}_{2} \mathrm{P}$. The proton acceptors are nonmetal sites having a small negative charge to trap protons (e.g., $\mathrm{O}$ of Glu23 in hydrogenase, -0.44 e; $\mathrm{S}$ in $\left.\mathrm{Ni}\left(\mathrm{PS}^{*}\right)(\mathrm{CO})\right]^{-},-0.4 \mathrm{e} ; \mathrm{N}$ in $\left[\mathrm{Ni}(\mathrm{PNP})_{2}\right]^{2+},-0.34$ e; $\mathrm{P}$ in $\mathrm{Ni}_{2} \mathrm{P}$, -0.07 e) [19]. The $\mathrm{P}$ species in MoP flakes are also slightly negatively charged. This charged nature is analogous to that of the proton acceptors in hydrogenase, its analogues, and $\mathrm{Ni}_{2} \mathrm{P}$. It is reasonable to postulate that the slightly charged $\mathrm{P}$ species in MoP work similarly to the proton acceptors in hydrogenase, its analogues, and $\mathrm{Ni}_{2} \mathrm{P}$, also contributing positively to the catalytic activity of MoP flakes. Therefore, the catalytic activity of MoP flakes is likely to be correlated with the charged natures of Mo and P.

Finally, the HER performance of MoP flakes in basic solution $(\mathrm{KOH}, 1 \mathrm{M})$ was evaluated. The results are summarized in Figure 13. The corresponding $\eta_{10}$ and $\eta_{20}$ is 166 and $184 \mathrm{mV}$, respectively (Figure 13(a)). Current density recorded in a potentiostatic electrolysis experiment shows slight decrease in $10000 \mathrm{~s}$, and the increase of $\eta_{20}$ after 2000 scan in repeated CV scans is as small as $14 \mathrm{mV}$ (inset of Figure 13(b)). In addition, the faradaic yield is also nearly 100\% within the experimental error (Figure 13(c)). These experiments demonstrate that MoP flake can also work efficiently and stably in basic solution for hydrogen generation.

\section{Conclusion}

In summary, MoP flake was found to show efficient and stable catalytic activity in HER in acidic and basic solution. The optimal $\eta_{20}$ of MoP flakes mixed with carbon black is as small as $155 \mathrm{mV}$ in acidic solution and 184 $\mathrm{mV}$ in basic solution. The fabrication temperature of MoP flakes was found to influence the catalytic activity of MoP flakes. The samples fabricated at $800^{\circ} \mathrm{C}$ showed superior performance to those at $750^{\circ} \mathrm{C}$ or $850^{\circ} \mathrm{C}$. The difference of catalytic activities might be associated with the crystallinity and specific surface area of products obtained at different temperatures. Charge transport resistances at the interface of catalyst/electrolyte suggest a Tafel slope of $71.77 \mathrm{mV} \cdot \mathrm{dec}^{-1}$, implying that a Volmer-Heyrovsky mechanism might be responsible for the HER process on the surface of MoP flakes. Potentiostatic electrolysis and accelerated degradation experiments show that MoP flakes can work stably in long-term hydrogen generation in both acidic and basic solution. In 


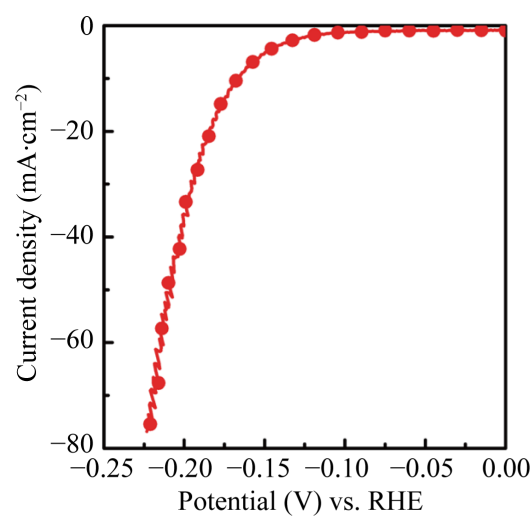

(a)

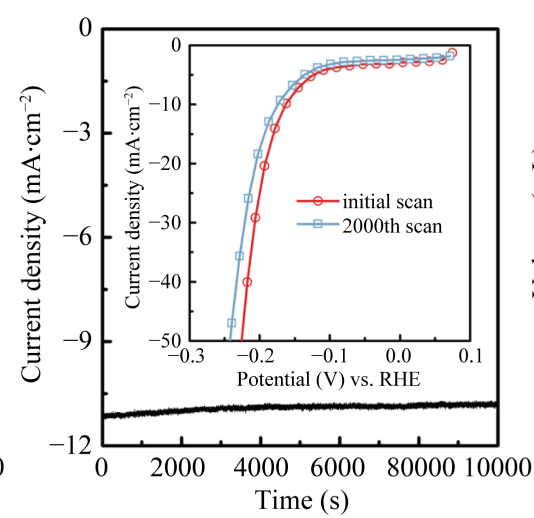

(b)

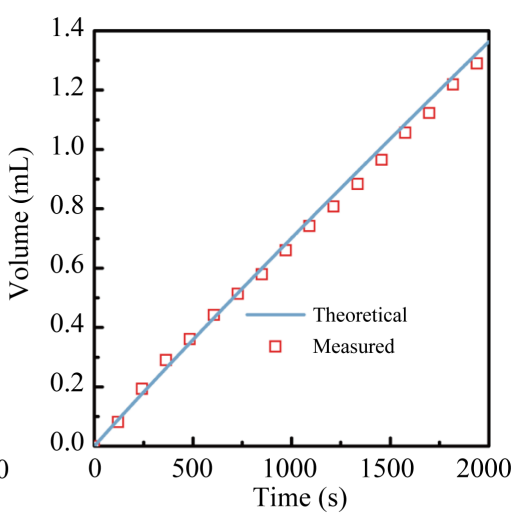

(c)

Figure 13. Evaluation of MoP/C on GCE in basic solution (KOH, 1M). (a) Polarization curve (loading amount: $1.14 \mathrm{mg} \cdot \mathrm{cm}^{-2}$ of MoP and $0.57 \mathrm{mg} \cdot \mathrm{cm}^{-2}$ of C). (b) The relationship of current density and experimental time in potentiostatic experiment (applied potential: -0.18 vs. RHE). Inset shows the polarization curves corresponding to the initial and 1000 th scan in CV sweep. (c) The plots of theoretical and measured volume of generated hydrogen in potentiostatic electrolysis experiment (applied potential: -0.28 vs. RHE). Only potentials in (a) were corrected with iR drop.

addition, the faradaic yield of MoP flakes in acidic and basic solution is nearly 100\%. XPS experiments reveal that $\mathrm{Mo}$ and $\mathrm{P}$ in MoP flakes have a slight charge, and the catalytic activity of MoP flakes might be associated with the charged natures of Mo and P.

\section{Acknowledgements}

This research was financially supported by the National Natural Science Foundation of China (61006049, 50925207), the Ministry of Science and Technology of China (2011DFG52970), the Ministry of Education of China (IRT1064), Jiangsu Innovation Research Team, the Education Department of Jiangsu (10KJB430004), Jiangsu Province (2011-XCL-019, and 2013-479), and Jiangsu University (09JDG043 and Outstanding Youth Project).

\section{References}

[1] Lewis, N.S. and Nocera, D.G. (2006) Powering the Planet: Chemical Challenges in Solar Energy Utilization. Proceedings of the National Academy of Sciences, 103, 15729-15735. http://dx.doi.org/10.1073/pnas.0603395103

[2] Cook, T.R., Dogutan, D.K., Reece, S.Y., Surendranath, Y., Teets, T.S. and Nocera, D.G. (2010) Solar Energy Supply and Storage for the legacy and Nonlegacy Worlds. Chemical Reviews, 110, 6474-6502.

http://dx.doi.org/10.1021/cr100246c

[3] Jaramillo, T.F., Jørgensen, K.P., Nielsen, J.H., Horch, S. and Chorkendorff, I. (2007) Identification of Active Edge Sites for Electrochemical $\mathrm{H}_{2}$ Evolution from $\mathrm{MoS}_{2}$ Nanocatalysts. Science, 317, 100-102. http://dx.doi.org/10.1126/science.1141483

[4] Laursen, A.B., Kegnaes, S., Dahl, S. and Chorkendorff, I. (2012) Molybdenum Sulfides-Efficient and Viable Materials for Electro- and Photoelectrocatalytic Hydrogen Evolution. Energy \& Environmental Science, 5, 5577-5591. http://dx.doi.org/10.1039/c2ee02618j

[5] Hinnermann, B., Moses, P.G., Bonde, J., Jørgensen, K.P., Nielsen, J.H., Horch, S., Chorkendorff, I. and Nørskov, J.K. (2005) Biomimetic Hydrogen Evolution: $\mathrm{MoS}_{2}$ Nanoparticles as Catalyst for Hydrogen Evolution. Journal of the American Chemical Society, 127, 5308-5309. http://dx.doi.org/10.1021/ja0504690

[6] Merki, D. and Hu, X. L. (2011) Recent Developments of Molybdenum and Tungsten Sulfides as Hydrogen Evolution Catalysts. Energy \& Environmental Science, 4, 3878-3888. http://dx.doi.org/10.1039/c1ee01970h

[7] Merki, D., Fierro, S., Vrubel, H. and Hu, X.L. (2011) Amorphous Molybdenum Sulfide Films as Catalysts for Electrochemical Hydrogen Production in Water. Chemical Science, 2, 1262-1267. http://dx.doi.org/10.1039/c1sc00117e

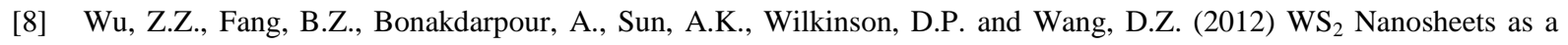
Highly Efficient Electrocatalyst for Hydrogen Evolution Reaction. Applied Catalysis B: Environmental, 125, 59-66. http://dx.doi.org/10.1016/j.apcatb.2012.05.013

[9] Voiry, D., Yamaguchi, H., Li, J.W., Silva, R., Alves, D.C.B., Fujita, T., Chen, M.W., Asefa, T., Shenoy, V.B., Eda, G. 
and Chhowalla, M. (2013) Enhanced Catalytic Activity in Strained Chemically Exfoliated WS 2 Nanosheets for Hydrogen Evolution. Nature Materials, 12, 850-855. http://dx.doi.org/10.1038/nmat3700

[10] Ivanovskaya, A., Singh, N., Liu, R.F., Kreutzer, H., Baltrusaitis, J., Nguyen, T.V., Metiu, H. and McFarland, E. (2013) Transition Metal Sulfide Hydrogen Evolution Catalysts for Hydrobromic Acid Electrolysis. Langmuir, 29, 480-492. http://dx.doi.org/10.1021/la3032489

[11] Kong, D.S., Cha, J.J., Wang, H.T., Lee, H.R. and Cui, Y. (2013) First-Row Transition Metal Dichalcogenide Catalysts for Hydrogen Evolution Reaction. Energy \& Environmental Science, 6, 3553-3558. http://dx.doi.org/10.1039/c3ee42413h

[12] Vrubel, H. and Hu, X.L. (2012) Molybdenum Boride and Carbide Catalyze Hydrogen Evolution in Both Acidic and Basic Solutions. Angewandte Chemie International Edition, 51, 12703-12706.

[13] Chen, W.F., Iyer, S., Iyer, S., Sasaki, K., Wang, C.H., Zhu, Y.M., Muckerman, J.T. and Fujita, E. (2013) Biomass-Derived Electrocatalytic Composites for Hydrogen Evolution. Energy \& Environmental Science, 6, 1818-1826. http://dx.doi.org/10.1039/c3ee40596f

[14] Chen, W.F., Wang, C.H., Sasaki, K., Marinkovic, N., Xu, W., Muckerman, J.T., Zhu, Y. and Adzic, R.R. (2013) Highly Active and Durable Nanostructured Molybdenum Carbide Electrocatalysts for Hydrogen Production. Energy \& Environmental Science, 6, 943-951. http://dx.doi.org/10.1039/c2ee23891h

[15] Harnisch, F., Sievers, G. and Schröder, U. (2009) Tungsten Carbide as Electrocatalyst for the Hydrogen Evolution Reaction in pH Neutral Electrolyte Solutions. Energy \& Environmental Science, 89, 455-458. http://dx.doi.org/10.1016/j.apcatb.2009.01.003

[16] Zhao, Y., Kamiya, K., Hashimoto, K. and Nakanishi, S. (2013) Hydrogen Evolution by Tungsten Carbonitride Nanoelectrocatalysts Synthesized by the Formation of a Tungsten Acid/Polymer Hybrid In Situ. Angewandte Chemie International Edition, 52, 13638-13641. http://dx.doi.org/10.1002/anie.201307527

[17] Cao, B.F., Veith, C.M., Neuefeind, J.C., Adzic, R.R. and Khalifah, P.G. (2013) Mixed Close Packed Cobalt Molybdenum Nitrides as Non-Noble Metal Electrocatalysts for the Hydrogen Evolution Reaction. Journal of the American Chemical Society, 135, 19186-19192. http://dx.doi.org/10.1021/ja4081056

[18] Tran, P.D., Chiam, S.Y., Boix, P.P., Ren, Y., Pramana, S.S., Fize, J., Artero, V. and Barber, J. (2013) Novel Cobalt/ Nickel-Tungsten-Sulfide Catalysts for Electrocatalytic Hydrogen Generation from Water. Energy \& Environmental Science, 6, 2452-2459. http://dx.doi.org/10.1039/c3ee40600h

[19] Liu, P. and Rodriguez, J.A. (2005) Catalysts for Hydrogen Evolution from the [NiFe] Hydrogenase to the $\mathrm{Ni}_{2} \mathrm{P}(001)$ Surface: The Importance of Ensemble Effect. Journal of the American Chemical Society, 127, 14871-14878. http://dx.doi.org/10.1021/ja0540019

[20] Popczun, E.J., McKone, J.R., Read, C.G., Biacchi, A.J., Wiltrout, A.M., Lewis, N.S. and Schaak, R.E. (2013) Nanostructured Nickel Phosphide as an Electrocatalyst for the Hydrogen Evolution Reaction. Journal of the American Chemical Society, 135, 9267-9270. http://dx.doi.org/10.1021/ja403440e

[21] Huang, Z.P., Chen, Z.B., Chen, Z.Z., Lv, C.C., Meng, H. and Zhang, C. (2014) $\mathrm{Ni}_{12} \mathrm{P}_{5}$ Nanoparticles as an Efficient Catalyst for Hydrogen Generation via Electrolysis and Photoelectrolysis. ACS Nano, 8, 8121-8129. http://dx.doi.org/10.1021/nn5022204

[22] Liu, Q., Tian, J.Q., Cui, W., Jiang, P., Cheng, N.Y., Asiri, A.M. and Sun, X.P. (2014) Carbon Nanotubes Decorated with CoP Nanocrystals: A Highly Active Non-Noble-Metal Nanohybrid Electrocatalyst for Hydrogen Evolution. Angewandte Chemie International Edition, 53, 6710-6714.

[23] Popczun, E.J., Read, C.G., Roske, C.W., Lewis, N.S. and Schaak, R.E. (2014) Highly Active Electrocatalysis of the Hydrogen Evolution Reaction by Cobalt Phosphide Nanoparticles. Angewandte Chemie International Edition, 53, 5427-5430.

[24] Walter, M.G., Warren, E.L., McKone, J.R., Boettcher, S.W., Mi, Q.X., Santori, E.A. and Lewis, N.S. (2010) Solar Water Splitting Cells. Chemical Reviews, 110, 6446-6473. http://dx.doi.org/10.1021/cr1002326

[25] Gao, M.R., Lin, Z.Y., Zhuang, T.T., Jiang, J., Xu, Y.F., Zheng, Y.R. and Yu, S.H. (2012) Mixed-Solution Synthesis of Sea Urchin-Like NiSe Nanofiber Assemblies as Economical Pt-Free Catalysts for Electrochemical $\mathrm{H}_{2}$ Production. Journal of Materials Chemistry, 22, 13662-13668. http://dx.doi.org/10.1039/c2jm31916k

[26] Phillips, D.C., Sawhill, S.J., Self, R. and Bussell, M.E. (2002) Synthesis, Characterization, and Hydrodesulfurization Properties of Silica-Supported Molybdenum Mhosphide Catalysts. Journal of Catalysis, 207, 266-273. http://dx.doi.org/10.1006/jcat.2002.3524

[27] Abu, I.I. and Smith, K.J. (2006) The Effect of Cobalt Addition to Bulk MoP and $\mathrm{Ni}_{2} \mathrm{P}$ Catalysts for the Hydrodesulfurization of 4,6-Dimethyldibenzothiophene. Journal of Catalysis, 241, 356-366. http://dx.doi.org/10.1016/j.jcat.2006.05.010

[28] Powell, C.J. (2012) Recommended Auger Parameters for 42 Elemental Solids. Journal of Electron Spectroscopy and 
Related Phenomena, 185, 1-3. http://dx.doi.org/10.1016/j.elspec.2011.12.001

[29] Nefedov, V.I., Salyn, Y.V., Domashevskaya, E.P., Ugai, Y.A. and Terekhov, V.A.A. (1975) Study by XPS and XRS of the Participation in Chemical Bonding of the 3d Electrons of Copper, Zinc and Gallium. Journal of Electron Spectroscopy and Related Phenomena, 6, 231-238. http://dx.doi.org/10.1016/0368-2048(75)80018-1

[30] Tian, J.Q., Liu,Q., Asiri, A.M. and Sun, X.P. (2014) Self-Supported Nanoporous Cobalt Phosphide Nanowire Arrays: An Efficient 3D Hydrogen-Evolving Cathode over the Wide Range of pH 0-14. Journal of the American Chemical Society, 136, 7587-7590. http://dx.doi.org/10.1021/ja503372r

[31] McKone, J.R., Sadtler, B.F., Werlang, C.A., Lewis, N.S. and Gray, H.B. (2013) Ni-Mo Nanopowders for Efficient Electrochemical Hydrogen Evolution. ACS Catalysis, 3, 166-169. http://dx.doi.org/10.1021/cs300691m

[32] Lin, T.W., Liu, C.J. and Lin, J.Y. (2013) Facile Synthesis of $\mathrm{MoS}_{3} /$ Carbon Nanotube Nanocomposite with High Catalytic Activity toward Hydrogen Evolution Reaction. Applied Catalysis B: Environmental, 134-135, 75-82. http://dx.doi.org/10.1016/j.apcatb.2013.01.004

[33] Chen, Z., Cummins, D., Reinecke, B.N., Clark, E., Sunkara, M.K. and Jaramillo, T.F. (2011) Core-Shell $\mathrm{MoO}_{3}-\mathrm{MoS}_{2}$ Nanowires for Hydrogen Evolution: A Functional Design for Electrocatalytic Materials. Nano Letters, 11, 4168-4175. http://dx.doi.org/10.1021/nl2020476

[34] Xie, J., Zhang, H., Li, S., Wang, R., Sun, X., Zhou, M., Zhou, J., Lou, X.W. and Xie, Y. (2013) Defect-Rich MoS Ul- $^{2}$ trathin Nanosheets with Additional Active Edge Sites for Enhanced Electrocatalytic Hydrogen Evolution. Advanced Materials, 25, 5807-5813. http://dx.doi.org/10.1002/adma.201302685

[35] Wang, T.Y., Liu, L., Zhu, Z.W., Papakonstantinou, P., Hu, J.B. and Li, M. (2013) Enhanced Electrocatalytic Activity for Hydrogen Evolution Reaction from Self-Assembled Monodispersed Molybdenum Sulfide Nanoparticles on an Au Electrode. Energy \& Environmental Science, 6, 625-633. http://dx.doi.org/10.1039/c2ee23513g

[36] Li, Y., Wang, H., Xie, L., Liang, Y., Hong, G. and Dai, H. (2011) MoS 2 Nanoparticles Grown on Graphene: An Advanced Catalyst for the Hydrogen Evolution Reaction. Journal of the American Chemical Society, 133, 7296-7299. http://dx.doi.org/10.1021/ja201269b

[37] Liao, L., Zhu, J., Bian, X.J., Zhu, L.N., Scanlon, M.D., Girault, H.H. and Liu, B.H. (2013) MoS $_{2}$ Formed on Mesoporous Graphene as a Highly Active Catalyst for Hydrogen Evolution. Advanced Functional Materials, 23, 5326-5333. http://dx.doi.org/10.1002/adfm.201300318

[38] Yan, Y., Ge, X., Liu, Z., Wang, J.Y., Lee, J.M. and Wang, X. (2013) Facile Synthesis of Low Crystalline MoS 2 Nanosheet-Coated CNTs for Enhanced Hydrogen Evolution Reaction. Nanoscale, 5, 7768-7771. http://dx.doi.org/10.1039/c3nr02994h

[39] Tran, P.D., Nguyen, M., Pramana, S.S., Bhattacharjee, A., Chiam, S.Y., Fize, J., Field, M.J., Artero, V., Wong, L.H., Loo, J. and Barber, J. (2012) Copper Molybdenum Sulfide: A New Efficient Electrocatalyst for Hydrogen Production from Water. Energy \& Environmental Science, 5, 8912-8916. http://dx.doi.org/10.1039/c2ee22611a

[40] Yang, J., Voiry, D., Ahn, S.J., Kang, D., Kim, A.Y., Chhowalla, M. and Shin, H.S. (2013) Two-Dimensional Hybrid Nanosheets of Tungsten Disulfide and Reduced Graphene Oxide as Catalysts for Enhanced Hydrogen Evolution. Angewandte Chemie International Edition, 52, 13751-13754. http://dx.doi.org/10.1002/anie.201307475

[41] Sun, Y., Liu, C., Grauer, D.C., Yano, J., Long, J.R., Yang, P. and Chang, C.J. (2013) Electrodeposited Cobalt-Sulfide Catalyst for Electrochemical and Photoelectrochemical Hydrogen Generation from Water. Journal of the American Chemical Society, 135, 17699-17702. http://dx.doi.org/10.1021/ja4094764 
Scientific Research Publishing (SCIRP) is one of the largest Open Access journal publishers. It is currently publishing more than 200 open access, online, peer-reviewed journals covering a wide range of academic disciplines. SCIRP serves the worldwide academic communities and contributes to the progress and application of science with its publication.

Other selected journals from SCIRP are listed as below. Submit your manuscript to us via either submit@scirp.org or Online Submission Portal.
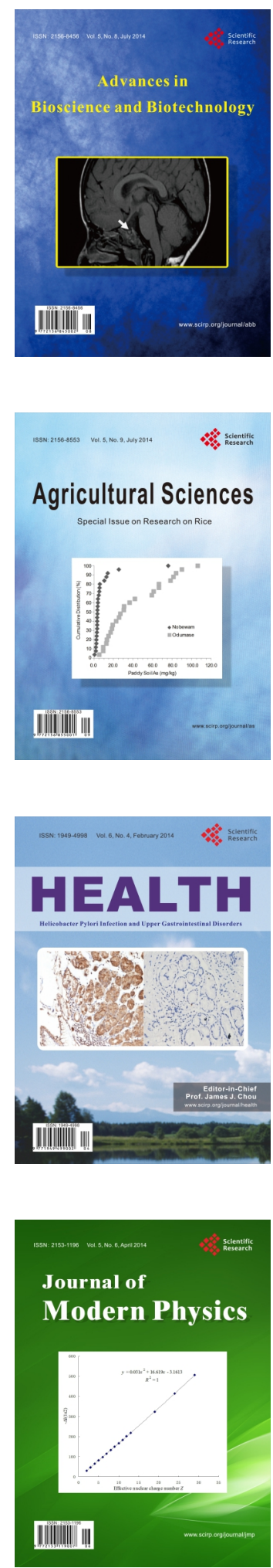
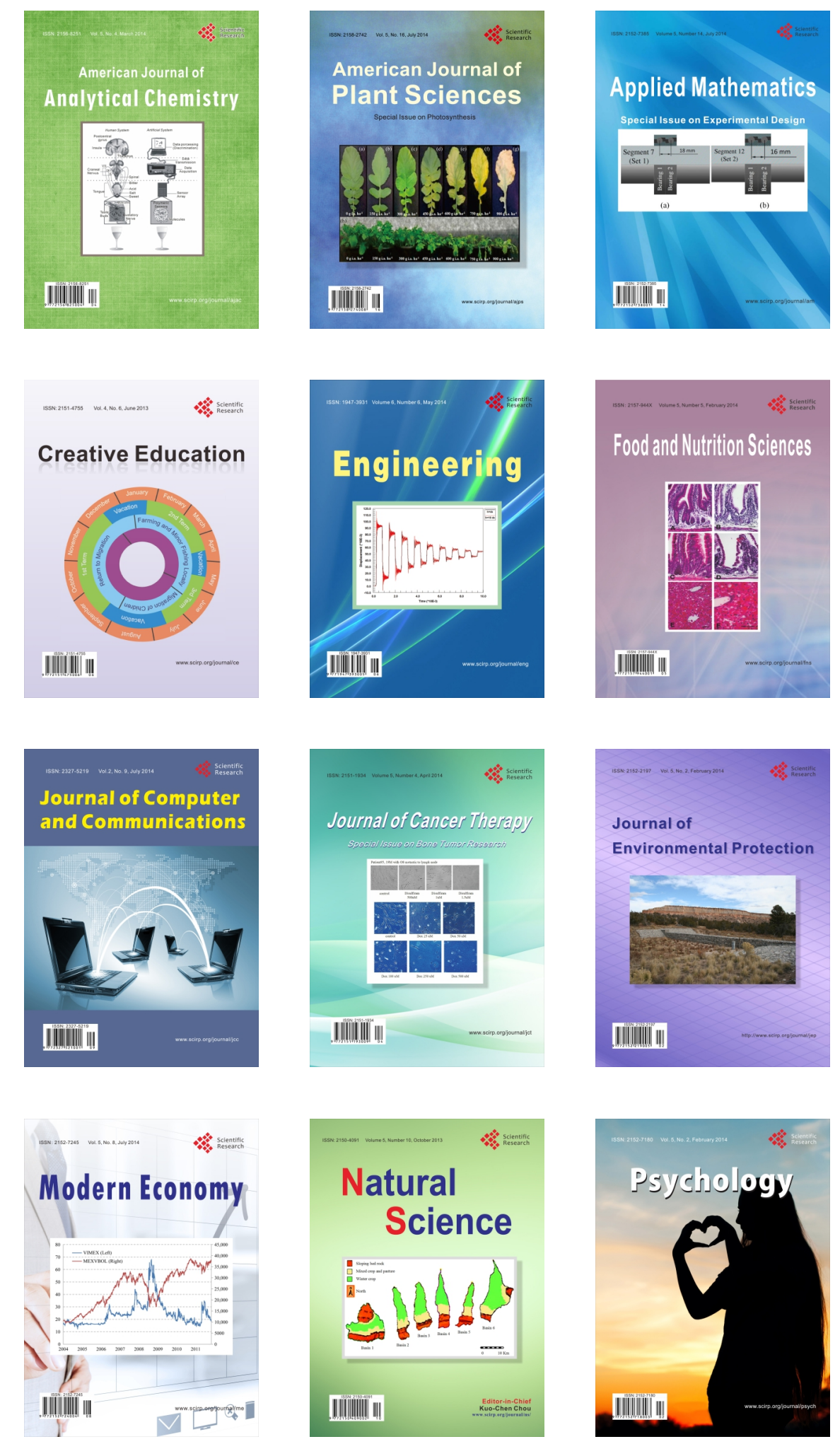